Portland State University

PDXScholar

1977

\title{
Listening Rate Preferences of Language Disordered Children as a Function of Grammatical Complexity
}

Wendy Lee Orloff

Portland State University

Follow this and additional works at: https://pdxscholar.library.pdx.edu/open_access_etds

Part of the Speech and Hearing Science Commons, and the Speech Pathology and Audiology Commons

Let us know how access to this document benefits you.

\section{Recommended Citation}

Orloff, Wendy Lee, "Listening Rate Preferences of Language Disordered Children as a Function of Grammatical Complexity" (1977). Dissertations and Theses. Paper 2545.

https://doi.org/10.15760/etd.2542

This Thesis is brought to you for free and open access. It has been accepted for inclusion in Dissertations and Theses by an authorized administrator of PDXScholar. Please contact us if we can make this document more accessible: pdxscholar@pdx.edu. 
AN ABSTRACT OF THE THESIS OF Wendy Lee Orloff for the Master of Science in Speech Communication presented June 1, 1977.

Title: Listening Rate Preferences of Language Disordered Children as a Function of Grammatical Complexity.

APPROVED BY MEMBERS OF THE THESIS COMMITTEE :
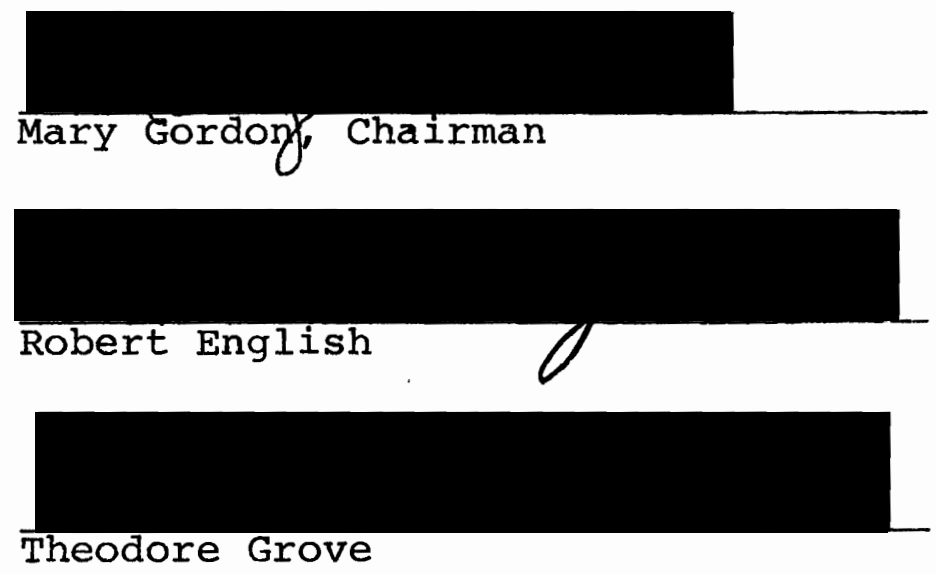

The purpose of this investigation was to determine if performance on a language comprehension task, varying in number of syntactical units (i.e., grammatical complexity) was affected by altered rates of speech. A total of twentyfour language disordered children, aged 7 years, 8 months, through 9 years, 8 months, who were enrolled in language/ learning disorders classrooms in the Portland Public Schools served as subjects. The Assessment of Children's Language Comprehension (Foster et al., 1972) test was administered to each subject via audio-tape at one expanded (100 wpm), one 
normal (150 wpm), and two compressed rates (200 wpm, $250 \mathrm{wpm}$ ) of speech.

The results of this investigation showed significant differences between performances at varying rates of speech. The normal speaking rate produced significantly better comprehension scores than the other rates. The fast speaking rate $(200 \mathrm{wpm})$ produced the next best scores, while the slow speaking rate (100 wpm) produced significantly lower scores. The results also indicated a normal speaking rate appears to be the best overall rate to use among language disordered subjects, regardless of grammatical complexity. 


\title{
LISTENING RATE PREFERENCES OF IANGUAGE DISORDERED CHIIDREN AS A \\ FUNCTION OF GRAMMATICAL \\ COMPLEXITY
}

by.

WENDY LEE ORLOFF

A thesis submitted in partial fulfillment of the requirements for the degree of

\author{
MASTER OF SCIENCE \\ in \\ SPEECH COMMUNICATION :
}

EMPHASIS IN SPEECH PATHOLOGY/AUDIOLOGY

Portland State University

1977 
TO THE OFFICE OF GRADUATE STUDIES AND RESEARCH:

The members of the Committee approve the thesis of Wendy Lee Orloff presented June 1, 1977.

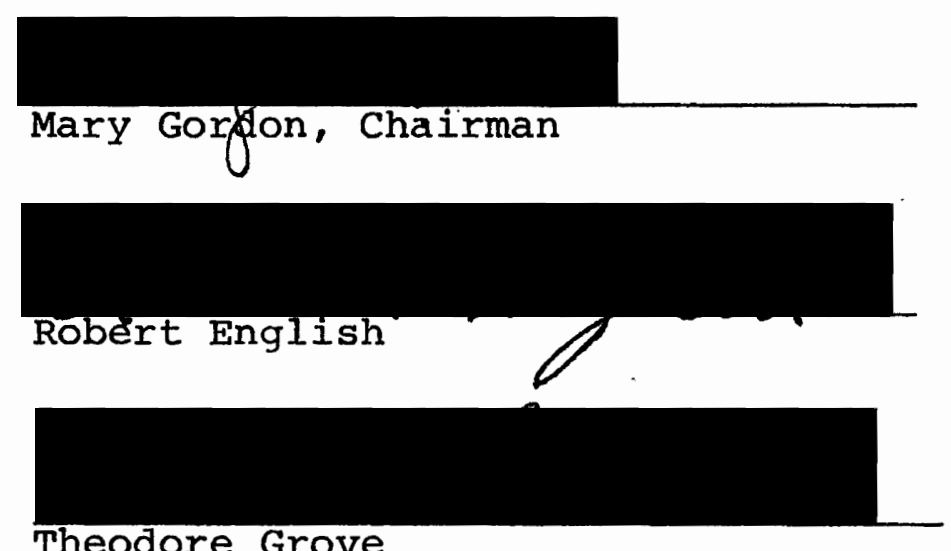

APPROVED :

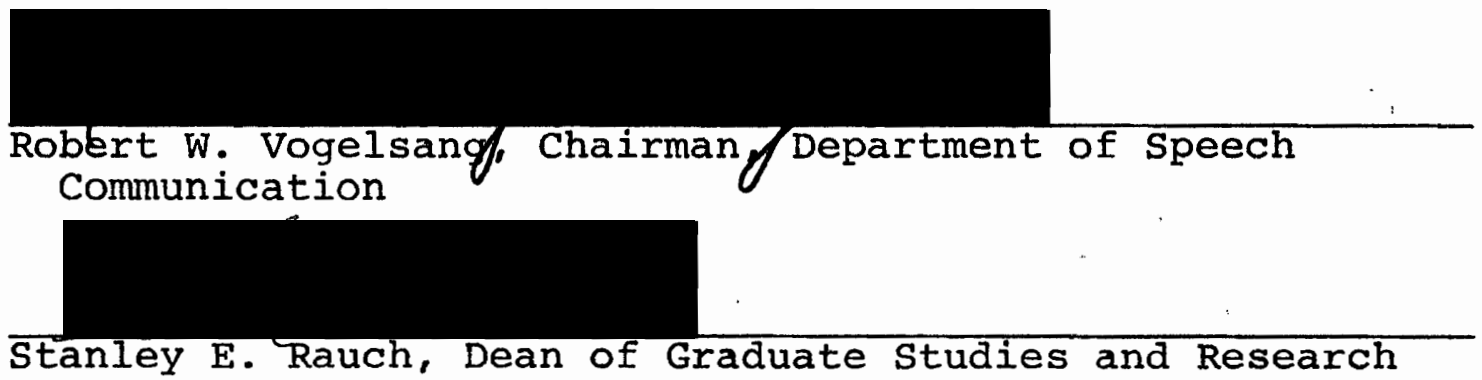

June 1, 1977 


\section{ACKNOWLEDGMENTS}

The support of many people has made this study possible. special thanks are extended to my committee chairman, Mary Gordon, for her patience and assistance throughout this project. Thanks go also to the members of my committee: Dr. Robert English for his encouragement and invaluable assistence with writing style, and $\mathrm{Dr}$. Theodore Grove for his guidance through B.J. Winer and statistical analysis.

A special thanks must go to Moore's Audio-Visual for their assistance with Vocom I. Without their aid and cooperation this study would not have been possible.

I wish to express many thanks to the supervisor, teachers, and children of the language/learning disorders classrooms in Portland Public Schools. Without their cooperation and patience, again, this study could not have been completed.

Finally, I wish to express my deepest love and appreciation to my sounding boards, Chester and Mona. They have been supportive throughout my educational career, and always available when needed. 
TABLE OF CONTENTS

PAGE

ACKNOWLEDGMENTS . . . . . . . . . . . . . .

LIST OF TABLES . . . . . . . . . . . . . . . . . vi vi

IIST OF FIGURES . . . . . . . . . . . . . . . . . vii v vi

CHAPTER

I INTRODUCTION . . . . . . . . . . . . 1

Introduction . . . . . . . . . . I 1

Statement of the Purpose . . . . . . 3

Operational Definitions . . . . . . . 3

II REVIEW OF THE LITERATURE . . . . . . . . . 6

Methods of Compressed Speech . . . . 6

Variables Affecting Compressed Speech . 8

Stimulus Variables

Organismic Variables

Rationale for Replication . . . . . 12

III METHODS AND PROCEDURES . . . . . . . . . . 14

Methods . . . . . . . . . . . . 14

Subjects

Test Stimuli

Instrumentation

Procedures . . . . . . . . .

PPVT Administration

$\overline{\text { ACLC }}$ Administration

Order of Rate Presentation

Data Analysis 
IV RESULTS AND DISCUSSION • • • • • • • • • •

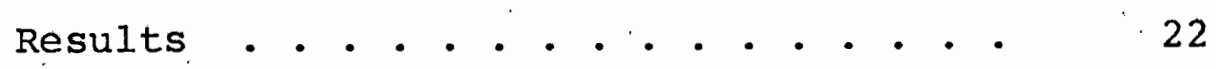

Discussion . . . . . . . . . . . 28

$\mathrm{V}$ SUMMARY AND IMPLICATIONS . . . . . . . . . . 34

Summary • • • • • • • • • • • • • 34

Implications . • . • . • . . . . 35

Clinical

Research 
LIST OF TABLES

TABIE

PAGE

I Order of Rate Presentation . . . . . . . .

II Order of Grammatical Complexity

Presentation . . . . . . . . . . .

III Pearson $r$ and $t$-Values for Four IQ/Subtest

Correlations • • • • • • • • • • • •

IV Analysis of Variance for Effect of Rate on

Subtest A Scores . . . . . . . . . .

$V$ Analysis of Variance for Effect of Rate on

Subtest B Scores . . . . . . . .

VI Analysis of Variance for Effect of Rate on

Subtest C Scores . . . . . . . . .

VII Analysis of Variance for Effect of Rate on

Subtest D Scores . . . . . . . . •

VIII F and Scheffe Critical $F$ Value Ratios for 12

A Posteriori Comparison for subtests

A B C and D Data . . . . . . . . . .

IX Subtest by Rate Total Scores . . . . . .

$X$ Pearson $r$ and $t-V a l u e s$ for Correlating

Degrees of Association Among Pairs of Subtests . . . . • . . . . . . • 


\section{LIST OF FIGURES}

FIGURE

PAGE

1 Illustration showing the Relationship of

Comprehension Totals to Rates . . . .

2 Illustration showing the Relationship of Comprehension Totals to Subtests. . . 
CHAPTER I

INTRODUCTION AND STATEMENT OF THE PROBLEM

\section{INTRODUCTION}

One of the primary avenues for acquiring information in school is through the auditory channel (Woodcock and clark, 1968a). Alteration of messages received through this input mode may have an affect on the child's ability to learn presented information. One possible way of altering the message is by changing the rate of presentation. Levine (1975) has suggested children with normal intelligence seem to have a preferred listening rate for receiving auditory stimuli which is dependent on the complexity of the message in terms of syntax and semantics. A variation of speaking rate, therefore, may have an affect on the amount and type of information comprehended.

The rate of presenting a message for a listening task can be manipulated in the following two ways: 1) compressed speech in which the time taken for a message to be presented has been reduced; and 2) expanded speech in which the time taken for a message to be presented has been increased. These alterations in speech rate can be accomplished by the following methods: 1) speaking rate, i.e., increasing or decreasing the normal speaking rate; 2) speed changing i.e., 
changing the playback speech of a recorded message; and 3) sampling method, i.e., mechanically deleting or adding portions of a recorded message. Because pitch, timbre, intensity, and apportionment of pause time remain unaffected in the sampling method, it seems to be the preferred method for compressing and expanding speech (Foulke, 1970).

Many studies of controlled speech rate have concentrated on variables affecting the comprehension of the spoken message. Intelligence (Sewe11, 1974), age (Levine, 1975), pre-test training and/or conditioning (Voor and Miller, 1965), grammatical complexity (Reid, 1968, and Aaronson, 1974), rate of presentation (Foulke, 1968; Carver, 1973; and Sewel1, 1974) are among the variables which have been investigated. Additionally, various types of populations have been studied to determine their comprehension of altered speech rates. These populations include mentally retarded (sticht, 1968), cerebral palsied and physically handicapped (deHopo, 1965), aphasic (dicarlo, 1972), blind (Foulke, 1967), and learning disabled (McCroskey, 1973).

One population of particular interest to the speech and language pathologist is the language/learning disordered. The language disabled child is one with normal or above average intelligence who fails to achieve his potential in academic situations due to atypical methods of learning (Berry, 1969, and McGrady, 1970). According to Eisenson (1968), these children have an impaired method for analyzing speech signals. One aspect of this analyzing problem may be the 
rate at which speech signals are presented. If a preferred rate of receiving speech signals can be determined, management programs may be adapted for the language disordered based on this preferred rate.

\section{STATEMENT OF THE PURPOSE}

The purpose of this investigation was to determine if auditory stimuli presented at different rates of speech affect the performance of language disordered subjects on language comprehension tasks at several levels of syntactical complexity. Specifically, the performances of language disordered subjects, ages 7 years, 8 months through 9 years, 8 months, on the four subtests of the Assessment of Children's Language Comprehension- $\underline{A C L C}$ (Foster, Stark, and Giddan, 1972) were compared at various rates of speech presentation. Answers to the following questions were sought:

1) At which rate of speech does the language disordered child have the greatest comprehension of speech?

2) Is there an overall preferred listening rate or does i.t vary according to the number of critical elements presented?

\section{OPERATIONAL DEFINITIONS}

The following operational definitions were used throughout this investigation.

\section{Language/Learning Disorders}

Language/learning disorders, as used in this study, was 
defined in accordance with the Education of All Handicapped Children Act of July 1975 which reads as follows:

Those children having a disorder in one or more of the basic psychological processes involved in understanding or using language, spoken or written, including such conditions as perceptual handicaps, brain injury, minimal brain dysfunction, and developmental aphasia, but excluding children who have learning problems which are primarily the result of visual, hearing, or motor handicaps, or mental retardation, or emotional disturbance, or of environmental, cultural, or economic handicaps.

The remainder of these definitions has been derived from a composite of sources (Fairbanks et al., 1957; Voor and Miller, 1965; Foulke, 1968; Broski, 1974; and Levine, 1975).

\section{Listening Rate}

The rate of speech, in words per minute, at which the listener is receiving information.

Preferred Listening Rate

The rate of speech, in words per minute, at which the listener most effectively comprehends information.

Speaking Rate

The rate, in words per minute, at which a message is delivered.

Comprehension

The understanding of a spoken message demonstrated by answering questions pertaining to the message presented. For the purpose of this investigation, comprehension will be 
determined by identifying an appropriate picture on the Assessment of Children's Language Comprehension.

Critical Element

A message consisting of a specified number of syntactic units or word classes with each unit corresponding to one critical element. The number of syntactic units corresponds to the grammatical complexity of the message. 


\section{CHAPTER II}

\section{REVIEW OF RELATED LITERATURE}

Compressed and expanded speech involve the perception of a recording which has been altered in the time required for it to be transmitted to the listener. Many variables affect the listener's ability to comprehend altered speech rates, and several studies have dealt with this concern. The purpose of this review, therefore, is threefold:

1) to discuss methods of compressing speech;

2) to discuss the research concerning the variables which affect comprehension of altered speech rates; and

3) to provide a rationale for the replication of a study relative to compressed speech.

\section{METHODS OF COMPRESSED SPEECH}

When the rate of a message varies, distortions may result in various parameters of the message such as pitch (and/or timbre), intensity, pause time, et cetera. The particular parameter or parameters affected depends on the methods of rate control used. Three major methods of rate control have been reported in the literature (Fairbanks et al., 1957; Foulke, 1970; and Primrose, 1975). The first method is speaking rapidly (Foulke, 1970). In speaking rapidly, the speech mechanism begins to malfunction over a period of time. 
Foulke (1970) reported the muscles involved in articulation become uncoordinated with a more rapid speech rate which ultimately results in poor or faulty articulation. In addition to faulty articulation, pitch, intensity, and pause time also may be distorted to the extent that speech perception become difficult.

The second method of rate-controlled speech reported by Foulke (1970) is the speed changing method. This method increases or decreases the rate of the message mechanically by changing the speed of a recorded message (e.g., tape recorder). A change in the frequencies that constutute the message occurs when speech is compressed in this manner. The patterns of variations in frequency, intensity, and apportionment of pause time remain the same, but the overall frequency and amount of inter-pause time are altered (Foulke, 1970). Finally there is the sampling method. Primrose (1975) described two sampling procedures: random compression, and selective compression. In random compression, microsecond portions of the taped message are randomly deleted. The amount of deletion is determined by the degree of compression desired, i.e., the amount of time into which the message is to be reduced (Primrose, 1975). In selective compression, there is a selective deletion of materials from the message. These materials consist mainly of pauses. At higher compression levels, or shorter durations of the message, portions of the sustained vowel are deleted (Primrose, 1975). In either method, two stages are required for compression. During the 
first stage, time samples of the input signal are extracted periodically, compressed (divided) in frequency, abutted in time and stored. During the second stage, the stored samples are then reproduced at a speed appropriate for restoration of the input frequencies (Fairbanks and Kodman, 1957). Foulke (1970) stated that patterns of variation in pitch, intensity, and apportionment of pause time are preserved, but the amount of inter-pause time is reduced. With the sampling method, the only affector of speech perception is the rate of the message itself and thus, the sampling method seems to be the preferred method for controlling rates of speech.

\section{VARIABLES AFFECTING COMPRESSED SPEECH}

Two types of variables affect the comprehension of time compressed and expanded speech, stimulus variables and organismic variables (Foulke, 1967). The first type involves the context in which the speech stimuli is presented as well as the characteristics of the signal itself, i.e., grammatical complexity, rate, and type of compression (Foulke, 1967). The second type of variable, the organismic variable, concerns itself with the listener, i.e., age, sex, intelligence, and relevant experiences.

Stimulus Variables

The first variables to be reviewed are those dealing with the stimulus. Foulke (1968), Foulke and sticht (1969), Carver (1973), and sewell (1974) have studied the rates of 
speech a listener can perceive before comprehension of the message is affected. These authors found that word rates up to 275 wpm (words per minute) have little affect in comprehension of a message; whereas, rates in excess of 275 wpm result in an increasing decline in listening comprehension. Foulke and sticht (1969) stated this finding implies that after a critical word rate is reached, a factor in addition to signal degradation contributes to the loss in comprehension. This factor concerns the processing mechanism of an individual. When the word rate becomes too great, the information cannot be processed as fast as it is received and partial loss of the message occurs, thereby, causing a decline in comprehension. Another stimulus variable that has been shown to affect listening comprehension is the difficulty of the message. Reid (1968) found that comprehension of time compressed speech depends on such characteristics of verbal material as grammatical complexity, vocabulary, and the abstractness of the message. Aaronson (1974), supporting Reid, observed as the speaking rate increases, the time required for processing complex sentences appears to exceed the message duration. Consequently, as the grammatical complexity and length of a message increases, comprehension of that message declines (Reid, 1968, and Aaronson, 1974).

In addition to rate of presentation and complexity of a message, inter-word pausing which is used in a message also affects the ability to comprehend time compressed and expanded speech. Aaronson (1974) found that inter-word pauses may 
be critical for encoding and decoding information. Similarly, Lass (1970) reported that "pause time appears to play a definite role in affecting perceptual judgements," and "if the pauses are too brief for the identifier to form an optimal representation of each word in a string, coding delays accumulate and degrade recall performance." Thus, it appears as listening rates increase and inter-pause time decreases, comprehension skills decline.

Conditioning or pre-training sessions for adptation to compressed/expanded speech is another stimulus variable affecting comprehension of altered speech rates. Experiments, such as those reported by orr and Friedman (1964) and Voor and Miller (1965) regarding pre-training sessions for a variable rate listening task, show that improvement was noted in comprehension after repeated trials (training) of listening to increased speech rates. Voor and Miller. (1965) in particular noted that adaptation to increased rates (380 wpm) takes approximately seven minutes of listening time, or exposure to 2,700 words or time compressed speech at the 380 wpm rate. Based on these authors' findings, pre-test training sessions appear to enhance comprehension scores and enable the listener to perceive variable speech rates more competently than if no pre-test sessions were given.

Organismic Variables

The majority of studies relative to time compressed speech have concerned themselves with a particular stimulus 
studied, but to a lesser extent. In particular, the organismic variables of sex, IQ, and age have been reported most often in the literature.

Orr and Friedman (1964) examined performances of rate varied speech tests among college aged students. The authors' results indicate no significant differences in comprehension occurred between groups of male and female listeners.

The research of Woodcock and Clark (1968a) showed a tendency for slower rates of speech to be more effective for children with lower intelligence. The subjects in their study had a mental age range of 9 years, 4 months (9-4) to 11 years, 3 months (11-3) with IQ groupings of 74-98, 90-110, and 102-121. Results of the Woodcock and Clark investigation showed those subjects with higher intelligence performed more efficiently at the compressed rates of 228 and 328 wpm than at the normal rate of 178 wpm. Those children of lesser intelligence did better with normal and slower speech rates than with compressed.

Studies by Woodcock and Clark (1968b) and Levine (1975) involving elementary school aged children revealed children can accommodate messages up to 275-300 wpm. Although test results based on $200 \mathrm{wpm}$ showed the highest comprehension scores, no one rate was indicated to be superior for any one age group. In fact, Levine's (1975) test results showed every child has his/her own individual preferred listening rate for presentation of recorded material. 
Population groupings, another facet of organismic variables (those affecting the listener), also have been reported in the literature. Bixler et al. (1961) and Foulke (1964) in their investigations, concurred that many blind individuals prefer increased listening rates of approximately $275 \mathrm{wpm}$. Normal college aged students cited in Levine's (1975) research showed listening rate preferences of approximately $207 \mathrm{wpm}$. Sticht (1968), in his study with subjects differing in aptitude levels, showed that the higher the aptitude level, the better comprehension of time compressed speech. In his study with cerebral palsied children, deHoop (1965) found that comprehension of speech at 175 wpm was better than comprehension of speech at the time compressed rate of $275 \mathrm{wpm}$. The findings of the above authors imply that preferred listening rates vary among different populations.

\section{RATIONALE FOR REPLICATION}

The language/learning disabled child is often encountered in the speech and language pathologist's caseload. If these children show a preference of rate for receiving information, then this information may be useful to the clinician in implementing effective management programs.

McCroskey (1973) investigated the language/learning disabled population for its ability to comprehend varying word rates. He found that rate did not influence comprehension when all scores were averaged; however, the youngest children (mean age 7-7) showed statistically significant 
differences in comprehension according to word rates favoring the slower, expanded rates (McCroskey, 1973).

In McCroskey's study the stimulus, as well as the organismic variables, were not all under enough experimental control to draw accurate conclusions. First, the age range of his 20 subjects was too broad (from 5 years to 17 years). Maturation and/or experiences thus, may have influenced the results. Second, the use of constant grammatical complexity revealed that syntactical knowledge of the older subjects may have affected the findings. Third, the unlimited pause time between questions provided time for the message to be decoded and encoded periodically preventing a continuous flow of varied rate presentation and the effects of that continuity. The fourth and final variable not under control in McCroskey's study was pre-test training. Adaptation to altered speech rates enables the listener to comprehend more optimally at the speech rate presented.

In order to find a preferred listening rate for language/learning disabled children, control of variables affecting comprehension of time compressed/expanded speech needed to be instigated. Thus, in replicating McCloskey's study, age, grammatical complexity, inter-question pause time, and pretest training needed to be included in the controlled variables. By including the above variables in a replication study, more accurate conclusions may be drawn from the results. 


\title{
CHAPTER III
}

\section{METHODS AND PROCEDURES}

\author{
METHODS
}

\section{Subjects}

The subjects for this study were twenty-four children with an age range of seven years, eight months (7-8), through nine years, eight months (9-8), with a mean age of eight years, eight months (8-8). All subjects had been diagnosed in the Portland Public Schools as language disordered, and they were enrolled in self-contained language disorders classrooms. Permission was obtained from the parent or guardian of each subject to participate in this study (See Appendix A for Permission Request Letter). Using a table of random numbers, the subjects were divided equally into four groups with each group receiving a different order of the treatment.

The variables controlled in this sample were age, auditory acuity, emotional organization, gross motor functioning, and language/learning disability.

Age. The children fell into a two year age range of 7-8 through 9-8.

Auditory Acuity. Normal hearing was determined by consulting the school records, the classroom teacher, speech clinician, or school nurse. 
Emotional organization. Emotional problems such as psychosis, neurosis, or personality disorders were determined by consulting the school records and/or classroom teacher. Children found having any identified problem of emotional disorganization were excluded from the study.

Gross Motor Functioning. Motor ability was determined by consultation with the classroom teacher and observation by this examiner. Those children with gross motor dysfunctions which would inhibit appropriate responses to the test materials were excluded from this investigation.

Language/Learning Disorders. Those children diagnosed with language disorders as a primary learning problem and enrolled in a self-contained, language/learning disorders classroom were included in this study.

Test Stimuli

Four subtests of the Assessment of Children's Language Comprehension ( $\underline{A C L C}$ ) were time compressed or expanded on Magnosonic Compact Casette tapes for later presentation to the subjects. The following procedures were utilized in obtaining the test stimuli:

1. The original recording of the $\underline{A C L C}$ was made on a Sony-Matic reel-to-reel tape recorder, Model TC 104, at $71 / 2$ ips with a Sony, MTL-F-96, microphone using the investigator's voice.

2. Each subtest of the ACLC was compressed to approximately $250 \mathrm{wpm}$ and $200 \mathrm{wpm}$ or expanded to approximately 100 
wpm on a separate cassette tape using a Vocom I speech compressor.

3. Five seconds of pause time were recorded between each question during which the subject was to respond.

4. The time compressed/expanded cassette tapes were played back to the subjects on a Sanyo Portable Cassette recorder, Model M1 102. For further specifications on the instruments used in this study, see Instrumentation specifications in Appendix B.

\section{Instrumentation}

Vocom I. Vocom I produced by PKM Corporation is an instrument which electromechanically shortens or lengthens pauses, vowels, and other redundant materials while maintaining a natural voice quality. This instrument selectively deletes or adds portions of a message. Selective deletion in this investigation consisted of taking a speech wave form and shortening or lengthening only the pauses (PKM Corp., 1972). The amount of compression and expansion was controlled by adjusting a dial control on the machine to the approximate compression or expansion desired.

Assessment of Children's Language Comprehension. The ACLC was designed to determine the level at which a child is able to process and remember lexical items in syntactical sequences when pictures are present (Foster, Stark, and Giddan, 1972). It is composed of four parts. Part A tests core vocabulary, and it is scored by comparing the number 
right to the total number of possible responses; and Parts $B, C$, and $D$ test increasing numbers of syntactical units or "critical elements," with scores expressed in percent (See Appendix C for Test Form).

Peabody Picture Vocabulary Test. The PPVT is a test which provides an estimation of a subject's verbal intelligence through measurement of hearing vocabulary (Dunn, 1965). No oral responses are required. The test consists of 150 words taken from Mirriam Webster's New Collegiate Dictionary. The test results yield a raw score which is the number of correct responses. This score can be converted into three types of derived scores: mental ability, intelligence quotient, and percentile equivalent (English, 1976).

\section{PROCEDURES}

\section{$\underline{\text { PPVT }}$ Administration}

The PPVT was administered by the author to all subjects according to the instructions outlined in the manual. Scores obtained from the administration of this test were used to determine intelligence quotients for each subject.

\section{$\underline{\text { ACLC }}$ Administration}

The ACLC was administered to all subjects via an audiotape prepared by the author. Each child responded to the administration of the test four times with each administration presented at a different rate. A minimum of one week separated adjacent test periods for any one child so that 
redundancy and familiarity of the task was minimized; the entire period of testing for each subject was four weeks. Each administration of the test was preceded with the subject listening to a 500 word high interest story of "Little Red Riding Hood" at the rate the test was to be administered. This procedure constituted a conditioning phase. Following this phase, the test was presented at the specified rate and a constant inter-question response time of five seconds was allowed for all treatments. The inter-question response time was controlled with a stop watch and was the same for all treatments due to possible decoding time differences affecting the scores.

\section{Order of Rate Presentation}

The order of rates at which the material was presented to the four groups was counterbalanced to control for order effects. The primary variance of interest in this study was rate of presentation of the materials and consisted of four levels: 100 words per minute (wpm) represented by Rs (rate slowed); 150 wpm represented by $\mathrm{Rn}$ (rate normal); $200 \mathrm{wpm}$ by Rf (rate fast); and $250 \mathrm{wpm}$ by RS (rate speeded). Table I graphically illustrates this research design which includes the counterbalanced order of the four rates at which the material was presented in relation to the four groups receiving these materials.

Each test consisted of the four subtests of the ACLC $(A, B, C$, and D); the subtests each increase in grammatical 
TABLE I

ORDER OF RATE PRESENTATION

Subject Groups

Order of Presentation ${ }^{a}$ 1st 2nd 3 rd 4 th

\begin{tabular}{lllll}
\hline Group I & Rs & RS & Rf & Rn \\
Group II & RS & Rf & Rn & Rs \\
Group III & Rf & Rn & Rs & RS \\
Group IV & Rn & Rs & RS & Rf \\
\hline
\end{tabular}

$a_{R s=100} \mathrm{wpm}, R S=250 \mathrm{wpm}, R f=200 \mathrm{wpm}$, and $R n=150 \mathrm{wpm}$

complexity. These subtests also were counterbalanced to control for adaptation and order effects (See Table II). Hence, this study investigated twenty-four subjects responding to four different rates of speech at four grammatical levels and produced comprehension scores for all subjects.

\section{Data Analysis}

Scoring of the ACLC was done according to the instructions outlined in the test manual. Data from sections A, B, $C$, and D consisted of sixteen total scores for each of twenty-four subjects, i.e., four scores, one at each of four different rates of presentation for each of four different levels of syntactical complexity. The data were analyzed in the following sequence. Four Pearson produce-moment correlation coefficients $(r)$ and their corresponding levels of 
TABLE II

ORDER OF GRAMMATICAL COMPLEXITY PRESENTATION

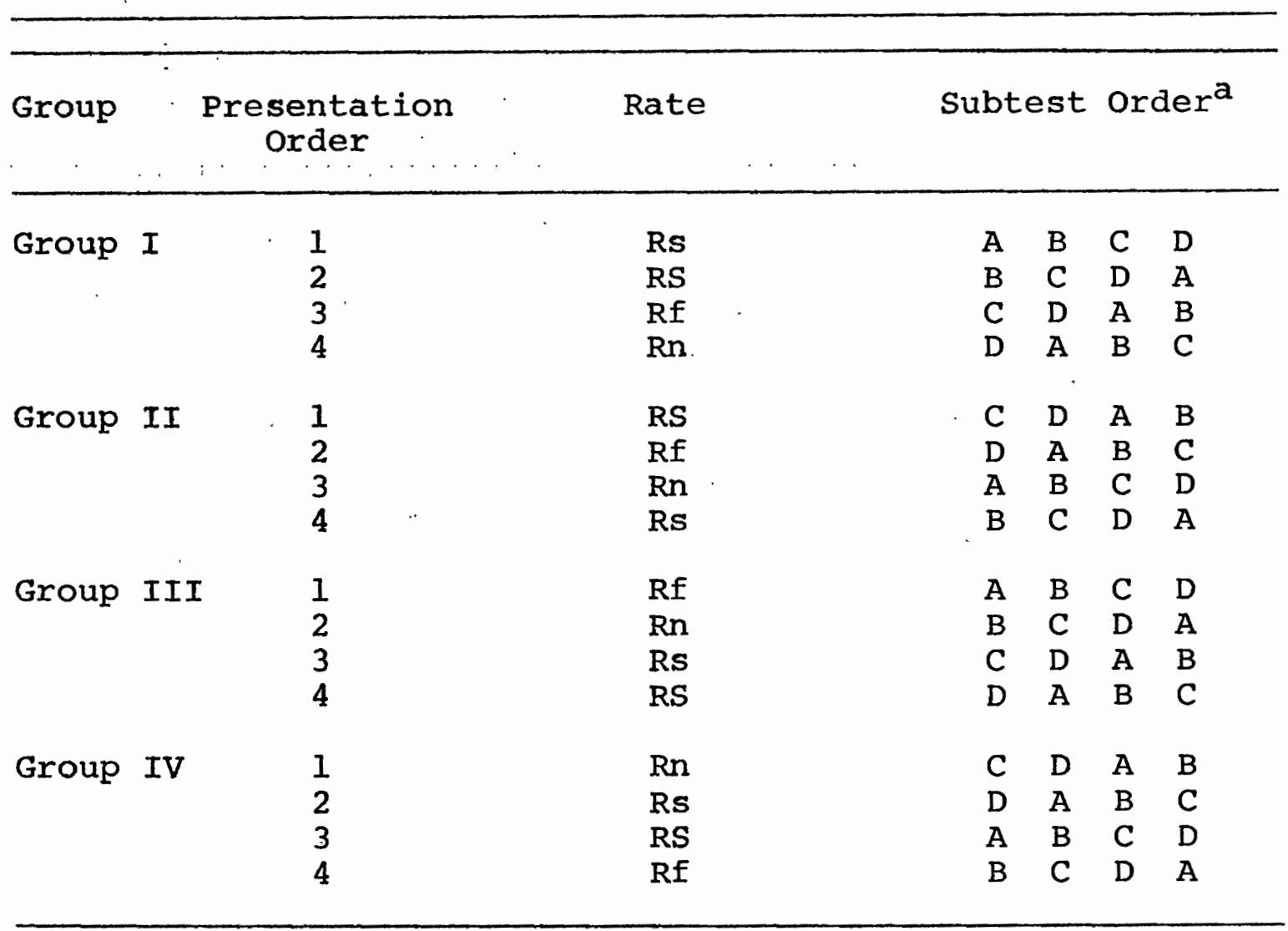

$a_{A=v o c a b u l a r y, ~} B=t$ wo critical elements, $C=t h r e e$ critical elements, and $D=$ four critical elements

statistical significance (t-scores) were computed to assess the relationship between subject IQ and each subtest. Four single factor repeated measures analyses of variance were computed for separate assessment of presentation rates on each performance. Where significant $\mathrm{F}$ ratios were obtained from the preceding analyses, a posteriori ${ }^{1}$ tests were

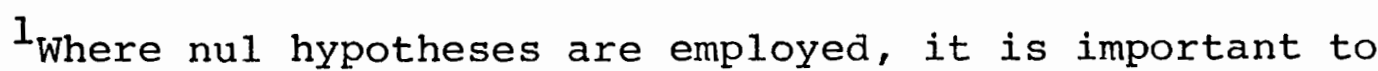
safeguard against Type I (false positive) errors where multiple t-tests are performed following significant $F$ 
completed on selected treatment comparisons following the Scheffe method for critical $F$ values. For additional information six Pearson product-moment correlation coefficients assessing association between all possible pairs of the four subtests and the corresponding levels of statistical significance were derived. All statistical operations were performed according to winer (1962).

ratios. Mention of a posteriori tests in the present study
refer to this safeguard. 
CHAPTER IV

RESULTS AND DISCUSSION

\section{RESULTS}

The purpose of this investigation was to determine if auditory stimuli presented at different rates of speech affect the performance of language disordered subjects on language comprehension tasks at several levels of syntactical complexity. Specifically, the performance of language disordered subjects, ages 7 years, 8 months through 9 years, 8 months, on the Assessment of Children's Language Comprehension (ACLC) were compared at various rates of speech presentation. The study sought to answer two questions posed at the beginning of this investigation and reiterated below. Preliminary to analyzing the data, IQ scores from the PPVT, representing an uncontrolled source of variance, were correlated with subtest scores in order to assess the relationship between intelligence and performance. AlI IQ/subtest correlations failed significance at the .05 level of confidence (See Table III). Therefore the IQ variable was excluded from the analysis of variance model in subsequent data analyses. At any rate in the repeated measures design employed here, where each subject is his own control; IQ and other individual difference variables are represented equally 
TABLE III

PEARSON $r$ AND $t$-VALUES FOR FOUR

IQ/SUBTEST CORRELATIONS

Subtest

Pearson $r$

$\underline{t-V a l u e} e^{*}$

\begin{tabular}{ccc}
\hline$A$ & .12 & .63 \\
$B$ & -.02 & .09 \\
$C$ & .30 & 1.76 \\
$D$ & .33 & 1.94 \\
\hline & $* t .05=2.07$ at df=22
\end{tabular}

across the several experimental treatments.

The first question posed was: At which rate of speech does the language disordered child have the greatest comprehension of speech? For example, will a language disordered child comprehend a message presented at a slow speaking rate better than one presented at a normal or faster speaking rate? Comprehension scores were obtained for each subtest (A, B, C, and D) at four different rates of speech (See Appendix D for Raw Data).

A repeated measures analysis of variance procedure was performed to assess the significance of differences among the four rates for each subtest (See Tables IV-VII). F ratios were significant at the .01 level of significance for all subtests, indicating the existence of significant variability among treatments for all subtests. In other words, presenta- 
TABIE IV

ANALYSIS OF VARIANCE FOR EFFECT OF RATE ON SUBTEST A SCORES

\begin{tabular}{|c|c|c|c|c|c|c|}
\hline Source of Variation & & ss & & $d f$ & MS & $\mathrm{F}^{*}$ \\
\hline Between people & & 618.50 & & 23 & & \\
\hline $\begin{array}{c}\text { Within people } \\
\text { Rate } \\
\text { Residual }\end{array}$ & $\begin{array}{l}1281.50 \\
1718.50 \\
\end{array}$ & 3000.00 & $\begin{array}{r}3 \\
69 \\
\end{array}$ & 72 & $\begin{array}{r}427.16 \\
24.90 \\
\end{array}$ & 17.15 \\
\hline Total & & 3618.50 & & 95 & & \\
\hline
\end{tabular}

TABLE V

ANALYSIS OF VARIANCE FOR EFFECT OF RATE ON SUBTEST B SCORES

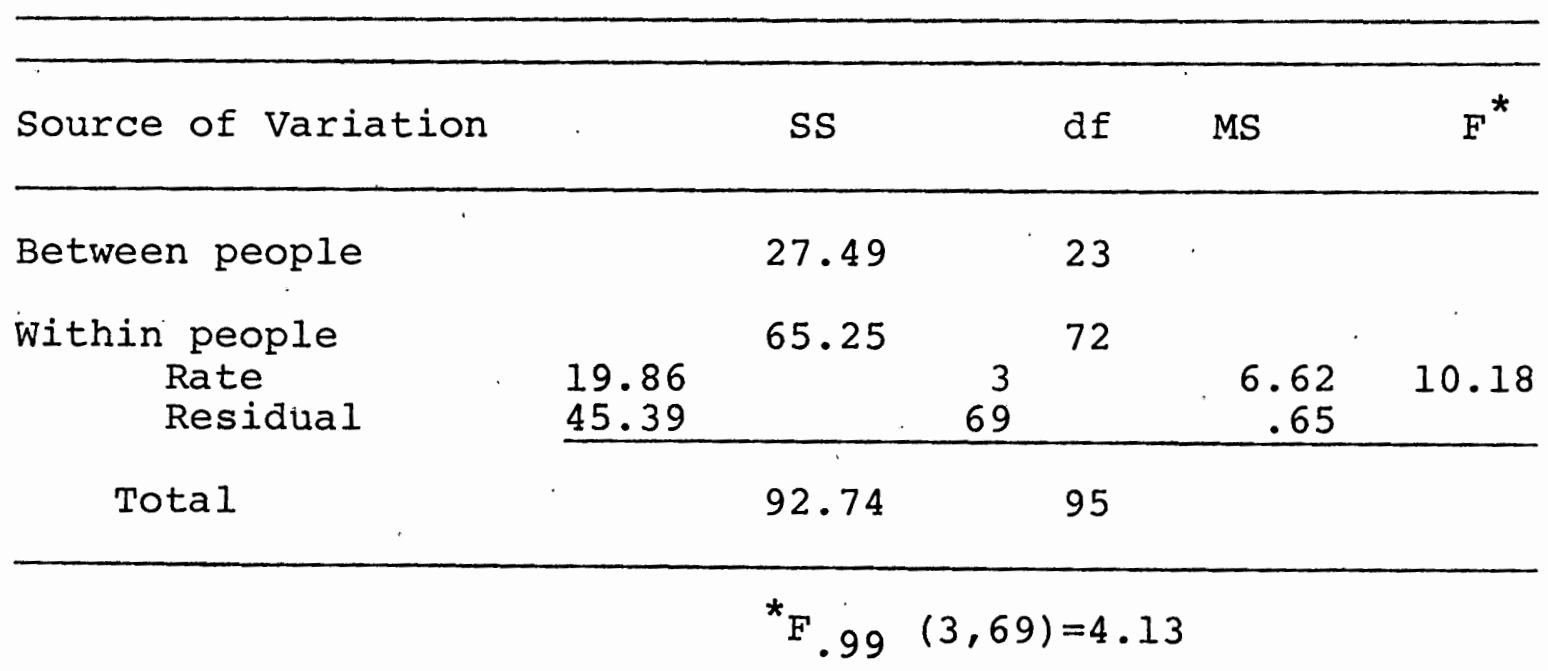

tion rate in all subtests did make a statistically significant difference.

After obtaining significant main effects on the rate variable, twelve a posteriori hypotheses were constructed 
TABLE VI

ANALYSIS OF VARIANCE FOR. EFFECT OF

RATE ON SUBTEST C SCORES

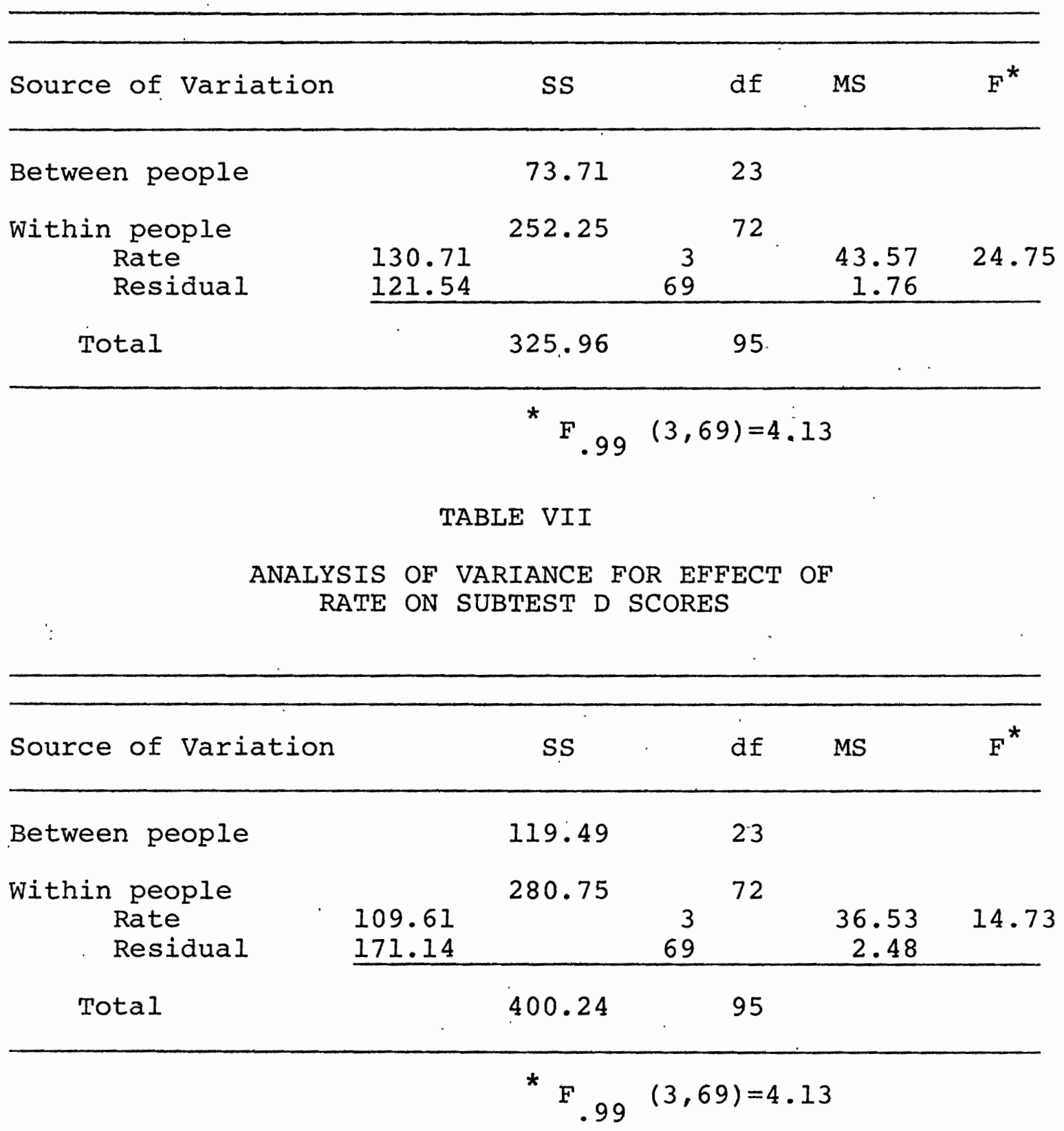

from inspection of treatment totals for rate in all subtests. Scheffe a posteriori tests were performed to assess the differences between these rate data in weighted comparisons. Results of a posteriori tests comparing rate treatments are 
summarized in Table VIII and consist of the following. For subtests $A, C$, and $D, R n$ produced significantly larger comprehension scores than rates $\mathrm{RS}+\mathrm{Rs}+\mathrm{Rf}$ in a weighted comparison. A posteriori weighted comparisons of Rf with RS + RS indicated significantly larger comprehension score values for $R f$ in subtests $A$ and $C$ but not in subtests $B$ and $D$. A posteriori, weighted comparisons of Rs with $R S+R n+R f$ showed significantly smaller comprehension scores in Rs for all subtests. In all, nine out of the twelve a posteriori hypotheses were supported by these data. Thus, rate normal produced the highest comprehension scores, while rate slow produced the lowest scores for all subtests.

The second question posed was: Is there an overall preferred listening rate, or does it vary according to the number of critical elements presented. For example, will a language disordered child, listening to compressed rates of speech, comprehend simple grammatical messages better than more complex ones?

Table IX and Figures 1 and 2 below present data on comprehension totals for rate and complexity, for rate alone,. and for complexity alone.

The data show a normal rate of presentation yields higher comprehension scores at all levels of grammatical complexity (subtests A, B, C, and D). Additionally, a heirarchy of preference for rate of presentation is shown in the data: i.e., rate normal was most preferred; rate fast was 
TABLE VIII

F AND SCHEFFE CRITICAL F VALUE RATIOS FOR 12 A POSTERIORI COMPARISONS

FOR SUTBTESTS A B C AND D DATA

\begin{tabular}{|c|c|c|c|}
\hline Subtest & $\begin{array}{l}\text { Comparison } \\
\text { Hypothesis }\end{array}$ & F & $\begin{array}{r}\text { Critice } \\
\text { Val }\end{array}$ \\
\hline A & $\begin{array}{l}3 R n>R S+R f+R s \\
2 R f>R S+R s \\
3 R s<R S+R f+R n\end{array}$ & $\begin{array}{l}16.50^{*} \\
17.15^{*} \\
45.62^{*}\end{array}$ & $\begin{array}{r}12.39 \\
8.26 \\
12.39\end{array}$ \\
\hline B & $\begin{array}{l}3 R n>R S+R f+R s \\
2 R f>R S+R s \\
3 R S<R S+R f+R n\end{array}$ & $\begin{array}{c}.58 \\
4.63 \\
30.04 *\end{array}$ & $\begin{array}{r}12.39 \\
8.26 \\
12.39\end{array}$ \\
\hline C & $\begin{array}{l}3 R n>R S+R f+R s \\
2 R f>R S+R s \\
3 R s<R S+R F+R n\end{array}$ & $\begin{array}{l}59.72 * \\
10.26 * \\
33.34 *\end{array}$ & $\begin{array}{r}12.39 \\
8.26 \\
12.39\end{array}$ \\
\hline D & $\begin{array}{l}3 R n>R S+R f+R s \\
2 R f>R S+R s \\
3 R s<R S+R f+R n\end{array}$ & $\begin{array}{c}31.08 * \\
7.86 \\
25.51 *\end{array}$ & $\begin{array}{r}12.39 \\
8.26 \\
12.39\end{array}$ \\
\hline
\end{tabular}

\footnotetext{
${ }^{*} F$ ratio is larger than the Scheffe critical value ${ }^{*}$ critical $\mathrm{F}$ values for $\mathrm{p}<.01$
}

next, speeded rate was next, and slowed rate was last. Some differences between listening rate preferences were statistically significant. Thus, the data indicate there appears to be an overall rate preference regardless of grammatical complexity.

From the available data it was interesting to note the degree of association between each part of the test with every other part. All six correlation coefficients were 
TABLE IX

SUBTEST BY RATE TOTAL SCORES

Comprehension Scores for Subtests

\begin{tabular}{|c|c|c|c|c|c|c|}
\hline \multirow{5}{*}{ 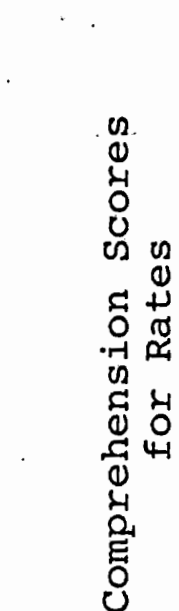 } & \multirow[b]{2}{*}{ Rs } & $\mathrm{A}^{1}$ & B & C & D & Total \\
\hline & & $188^{\circ}$ & 212 & 154 & 143 & 697 \\
\hline & RS & 217 & 237 & 173 & 168 & 795 \\
\hline & $R f$ & 227 & 235 & 189 & 182 & 833 \\
\hline & $\mathrm{Rn}$ & 234 & 239 & 230 & 214 & 917 \\
\hline & & 866 & 923 & 746 & 707 & \\
\hline
\end{tabular}

${ }^{1}$ Divided by 5 for comparability.

significant beyond the .05 level of confidence and ranged from .47 for $\mathrm{rBD}$ to .80 for $\mathrm{rAB}$ (See Table $\mathrm{X}$ ).

\section{DISCUSSION}

The findings from this study indicate that language disordered children's performances on a comprehension task are best at normal speaking rates of 150 wpm rather than at $200 \mathrm{wpm}, 250 \mathrm{wpm}$, or $100 \mathrm{wpm}$. In addition, the performances at all levels of grammatical complexity were best at normal speaking rates.

The results relative to the first question tend to 


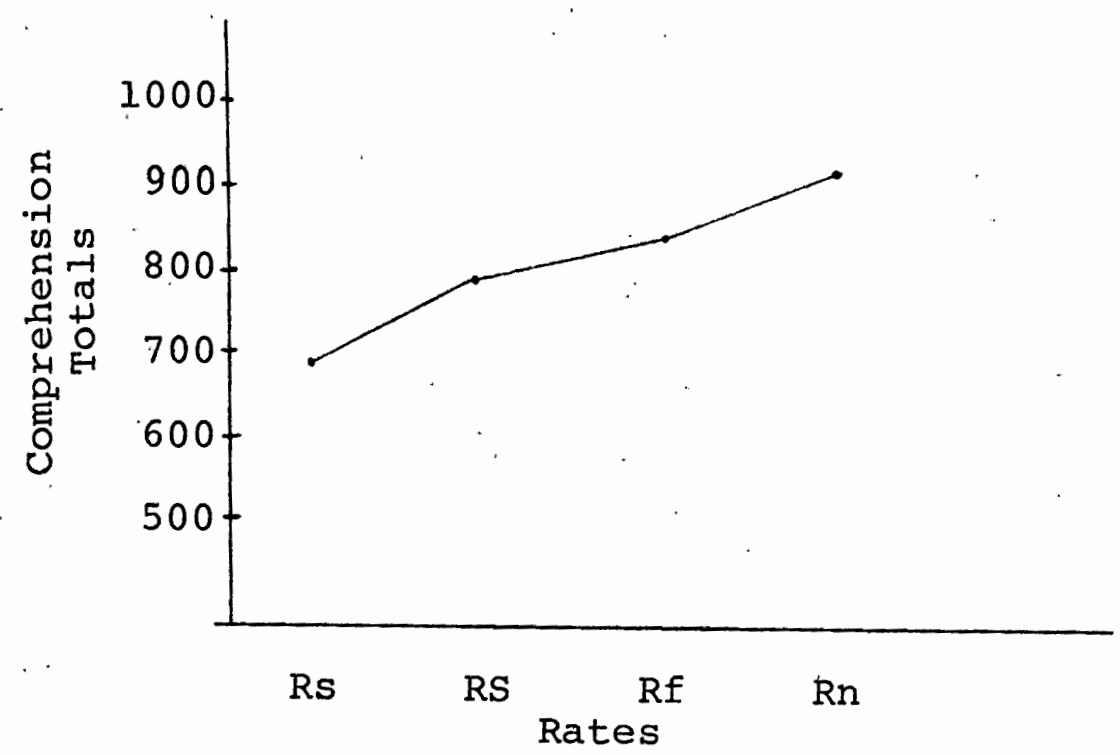

Figure 1. Illustration showing the relationship of comprehension totals to rates.

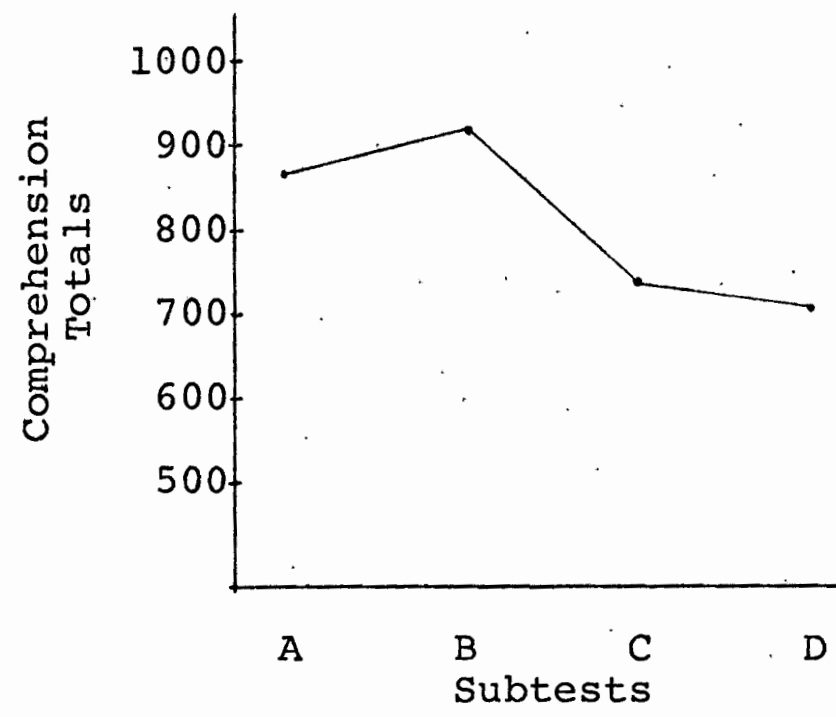

Figure 2. Illustration showing the relationship of comprehension totals to subtests.

contradict McCroskey's (1973) finding whereby rate did not influence comprehension of language disabled children when all scores were averaged. The language disordered subjects in this investigation showed a significant preference for normal 
TABLE X

\section{PEARSON $r$ AND $t$-VALUES FOR \\ CORREIATING DEGREES OF \\ ASSOCIATION AMONG \\ PAIRS OF SUBTESTS}

\begin{tabular}{ccc}
\hline Subtest pairs & $r$ & $\underline{t}$-Value* \\
\hline rAB & .80 & 8.88 \\
rAC & .74 & 7.40 \\
$r A D$ & .50 & 3.33 \\
$r B C$ & .60 & 4.61 \\
$r B D$ & .47 & 3.13 \\
$r C D$ & .72 & 6.54 \\
\hdashline & ${ }^{*}{ }_{t} .05=2.07$ at $d f=22$
\end{tabular}

speaking rates; whereas, slow speaking rates produced the most unsatisfactory. results.

Aaronson (1974) and Reid (1968) seem to agree as the grammatical complexity and rate of presentation increases, comprehension of a message declines. The results from this study showed significant differences between performances at various grammatical complexity levels; however, the findings did not support the notion that decline in comprehension occurs because of more rapid rates of speech. The subjects in this study showed that for all levels of grammatical complexity slow rates produced the most inadequate performance scores. 
Listening rate preferences of different populations were reported in the review of the literature, and this investigation tended to support the general findings that preferred listening rates vary among different populations. That is to say, unlike the blind (Foulke, 1967, and Levine, 1975) and college student populations (Levine, 1975), and similar to the cerebral palsy population of deHoop (1968), the language disordered children, as a group, comprehended normal speaking rates better than time expanded or compressed rates. Hence, the language disordered population showed a preferred listening rate of approximately $150 \mathrm{wpm}$.

Two possible rationales for lower comprehension scores at the slowed rate are poor attention span, and poor auditory memory. On the one hand, a longer or expanded message requires increased periods of attending. If a lag in attention occurs, part of the message meaning may be lost. On the other hand, with time expanded messages, segments of the message appear to be processed as they occur rather than after completion of the total message. Forgetting of beginning or contextual portions of the input may occur. The remaining elements of the message, received through the memory process, may be insufficient for complete comprehension of the message. Thus, with language disordered children, either of these disabilities, attention span and/or auditory memory, may have contributed to lower performances at the expanded rate. Additionally, it is interesting to note the high correlation between pairs of subtests. Although a limited amount 
of correlation should exist between pairs of subtests (the highest correlation between subtest pairs $A B, B C$, and $C D$; the next highest between subtests $A C$ and $B D$, and the lowest correlation between subtests $A D)$, the obtained correlation suggests redundancy in the subtests. Due to the high correlation found between subtests, one wonders about the value of giving the entire test.

As with many investigations, results of a study may vary with a change in the design of the procedures. For example, in this study, a longer conditioning phase may have produced more substantial comprehension scores making the differences between the varying rates less significant. Voor and Miller (1965) used seven minutes of listening time, or. exposure to 2,700 words of time compressed speech at $380 \mathrm{wpm}$. This study used only a 500-word passage. An increase in the amount of pre-test conditioning may produce less significant or non-significant differences among the performances at the varying rates of speech.

Another limitation of this study concerns the type of expanded speech. Vocom I selectively expanded speech by expanding pauses within a message. This type of expansion resulted in a message with pauses between syllables as well as between words. Such a stimulus resembles a sound blending exercise. The possible inability of language disordered subjects to perform sound blending tasks may have affected the results. 
33

In conclusion, a normal speaking rate appears to be the most appropriate rate of delivering messages to language disordered subjects. The significant differences between normal speaking rates and the other rates indicate the use of slow, fast, or speeded speech may have an adverse affect on comprehension performances among this population. The hierarchy of preference shows the fast rate will have less of an adverse affect than the speeded rate, and the slow rate will have the most adverse affect. 


\section{CHAPTER V}

\section{SUMMARY AND IMPLICATIONS}

\section{SUMMARY}

The purpose of this investigation was to determine if performance on a language comprehension task, varying in number of syntactical units (i.e., grammatical complexity) was affected by altered rates of speech. A total of twentyfour language disordered children, aged 7 years, 8 months, through 9 years, 8 months who were enrolled in language/ learning disorders classrooms in the Portland. Public Schools served as subjects. The Assessment of Children's Language Comprehension (Foster, et al., 1972) test was administered to each subject via audio-tape at one expanded rate (100 wpm), one normal rate (150 wpm) and two compressed rates $(200 \mathrm{wpm}$, $250 \mathrm{wpm})$ of speech.

The results of this investigation showed significant differences between performances at varying rates of speech. The normal speaking rates produced significantly better comprehension scores than the other rates. The fast speaking rate $(200 \mathrm{wpm})$ produced the next best scores, while the slow speaking rate $(100 ; \mathrm{wpm})$ produced significantly lower scores. The results also indicated a normal speaking rate appears to be the best overall rate to use among language 
disordered subjects, regardless of grammatical complexity.

\section{IMPLICATIONS}

\section{Clinical}

The data from this investigation showed individuals working with language disordered children should use normal speaking rates of approximately $150 \mathrm{wpm}$ when delivering instructions or information. Additionally, the data indicated the speaking rate should remain at approximately $150 \mathrm{wpm}$ regardless of the grammatical complexity within the message being presented.

\section{$\underline{\text { Research }}$}

The data from this study indicated normal speaking rates produced the most effective comprehension scores, and that slow speaking rates yielded the lowest comprehension scores. Further research is needed to determine if other sampling methods (i.e., non-selective methods) of compressed/ expanded speech generate the same results.

Although stimulus variables affecting the comprehension of varied speech rates were controlled according to those variables reported in the literature, there is a need to verify if other stimulus variables affect comprehension of time compressed/expanded speech. Such variables may include abstractness of the message and/or vocal inflection.

In addition, it would be interesting to conduct a study which would determine the amount of conditioning 
needed at varying rates of speech in order to perform most effectively on a language comprehension task. The data could be collected in terms of number of words required for specific performances and/or amount of exposure time needed for specific performances.

of final interest would be to determine if the amount of time needed for encoding and decoding varied at different rates of speech presentation. For example, if compressed speech showed longer periods needed for optimal encoding or decoding, then the advantage of compressing speech is questionable if reduced time is a serious consideration.

Because research on time compressed/expanded speech shows so much variability in its results, more investigations are needed to determine the actual effectiveness of rate altered speech. The suggestions made above are a few possibilities for future studies. 


\section{REFERENCES CITED}

AARONSON, D., Stimulus factors and listening strategies in auditory memory: A theoretical analysis. Cognitive Psychology, 6, 108-132 (1974).

BERRY, M., Language Disorders of Children: The Bases and Diagnoses. New York, N.Y.: Appleton-Century-Crofts (1969).

BIXLER, R., FOULKE, E. et al., Comprehension of rapid speech by the blind: Part $I$. Cooperative research project report no. 1005, Office of Education, Washington D.C. (1961).

BROSKI, D., Auditory learners and comprehension of rate altered recordings. Consortium on Auditory Learning Materials for the Handicapped, Washington D.C., May 1974.

CARVER, R., Effects of increasing the rate of speech presentation upon comprehension. Journal of Educational Psychology, 65, 118-126 (1973).

DEHOOP, W., Listening comprehension of cerebral palsied and other crippled children as a function of two speaking rates. Exceptional Children, 31, 233-240 (1965).

DICARLO, L., The influence of compression and expansion on the intelligibility of speech by young and aged aphasic (demonstrated CVA) individuals. Journal of Communication Disorders, 5, 299-306 (1972).

DUNN, L., Peabody Picture Vocabulary Test. Circle Pines, Minnesota: American Guidance Service Inc. (1965).

EDUCATION OF ALL HANDICAPPED CHILDREN ACT, July 1975.

EISENSON, J., Developmental aphasia: A speculative view with therapeutic implications. Journal of speech and Hearing Disorders, 33, 3-13 (1968).

ENGLISH, R. (Ed.), Examination of the Linguistic Process: A Compendium of Student Abstracts $(1970-1976)$. Portland, Oregon: - speech and Hearing sciences, Department of Speech Communication, Portland State University (1976). 
FAIRBANKS, G., GUTTMAN, N., and MIRON, M., Auditory comprehension of repeated high speed messages, Journal of speech and Hearing Disorders, 22, 20-22 (1957).

FAIRBANKS, G. and KODMAN, F., Word intelligibility as a function of time compression. The Journal of the Acoustical Society of America, $29, \frac{1}{636-641 \text { (1957) }}$.

FOSTER, R., STARK, J., and GIDDAN, J., Assessment of Children's Language Comprehension. Palo Alto, California: Consulting psychologists press Inc. (1972).

FOULKE, E., The comprehension of rapid speech by the blind: Part II. Cooperative research project report number 1370. Office of Education, Washington D.C. (1964).

, The comprehension of rapid speech by the blind: Part III. Interim progress report project number 2430, Office of Education, Washingtion D.C. (1967).

, Listening comprehension as a function of word rate. Journal of Communication, 18, 198-206 (1968).

, Methods of controlling the word rate of recorded speech. Journal of Communication, 20, 305-314 (1970).

FOULKE, E. and STICHT, T. G., Review of research on the intelligibility and comprehension of accelerated speech. Psychological Bulletin, 72, 50-62 (1969).

LASS, N., The significance of intra- and intersentence pause times in perceptual judgements of oral reading rate. Journal of Speech and Hearing Research, 13, 777-785 (1970).

LEVINE, S. J., An examination of listening rate. Monograph Series I, Consortium on Auditory Learning Materials for the Handicapped, Washington D.C., June 1975.

MCCROSKEY, R., Comprehension of rate controlled speech by children with specific learning disabilities. Journal of Learning Disabilities, 6, 621-627 (1973).

MCGRADY, H., Visual and auditory learning processes in normal children and children with specific learning disabilities. Exceptional Children, 36, 581-588 (1970).

ORR, D. and FRIEDMAN H., Research on speeded speech as an educational medium. Project report number 7-48-7670203, Department of Health Education and Welfare, Washington D.C. (1964). 
PRIMROSE R., College students' preference for compressed speech lectures, Department of Health Education and Welfare, Washington D.C. (1975).

PKM CORPORATION, Comparison of Compression Methods. Vocom Applications Bulletin. St. Paul, Minnesota: PKM Corp. (1972).

REID, R., Grammatical complexity and comprehension of compressed speech. Journal of Communication, 18, 236-242 (1968).

SEWELL, E., The role of compressed speech in attention research. Paper presented at the International Communication Assoc., New Orleans (1974).

STICHT, T., Some relationships of mental aptitude, reading ability, and iistening ability using normal and timecompressed speech. Journal of Communication, 18, 243-258 (1968).

VOOR, J. and MILLER, J., The effect of practice upon the comprehension of time-compressed speech. Speech Monographs, 32, 452-454 (1965).

WINER, B. J., Statistical Principles in Experimental Design. New York: McGraw-Hill Book Co., Inc. (1962).

WOODCOCK, R. and CLARK, C., Comprehension of a narrative passage by elementary school children as a function of listening rate, retention period, and IQ, IMRID papers and reports no. 2, George Peabody College for Teachers (1968a).

WOODCOCK, R., and CLARK, C., Differences in learning through compressed speech as a function of presentation strategy and rate among culturally disadvantaged fourth grade children. IMRID papers and reports no. 9, George Peabody College for Teachers (1968b). 


\section{APPENDIX A \\ PERMISSION REQUEST LETTER}

March 18, 1977

Dear Parents:

I am a graduate student at Portland State University and I am conducting a study with language disordered children. I am attempting to find out more about the listening skills of language disordered children and the results of this study should help teachers plan and organize school programs.

This study can be accomplished by administering the following evaluation instruments: The peabody Picture Vocabulary Test, and The Assessment of Children's Language Comprehension Test.

The evaluation will be done by myself, Wendy orloff, on four different days, Each day will take approximately 20 minutes of your child's time. In no way will your child's name be used in reporting the results of this, study.

Please sign below indicating your approval, and return with your child to school tomorrow.

Thank you for your help.

Wendy orloff

Graduate Student, Speech and Hearing Sciences

Portland State University

245-6891

CHILD'S NAME

PARENT'S SIGNATURE

DATE 


\section{APPENDIX B}

\section{INSTRUMENTATION SPECIFICATIONS}

Sanyo Portable Cassette Recorder Model Ml 102

Frequency Response: 150-5, 000 Hz

Signal-to-Noise Ratio: $30 \mathrm{~dB}$

Wow and Flutter: $0.6 \%$ (overall) RMS

Vocom I Speech Compressor

Frequency Response: $\pm 3 \mathrm{~dB}$ bandwidth $40 \mathrm{~Hz}$ to $10,000 \mathrm{~Hz}$ Signal-to-Noise Ratio: Minimum of $45 \mathrm{~dB}$ Wow and Flutter: Less than $0.25 \%$ 


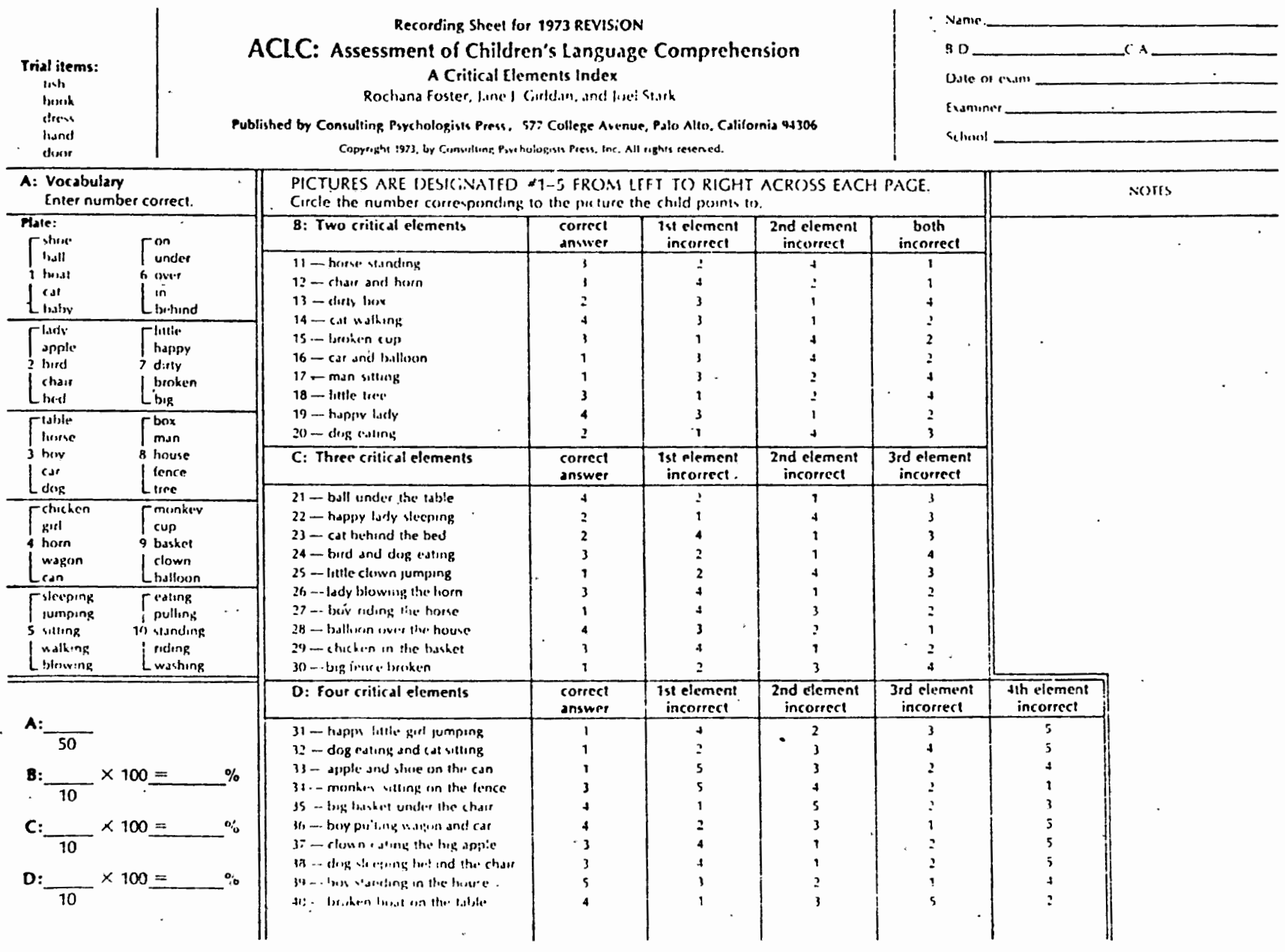




\section{APPENDIX D}

RAW DATA

GRAND AND TOTAL VALUE SCORES FOR

VARIOUS RATES IN SUBTEST D

OF ACLC

\begin{tabular}{|c|c|c|c|c|c|}
\hline subject & $\begin{array}{l}\text { Rate slow } \\
\text { (100 wpm) }\end{array}$ & $\begin{array}{l}\text { Rate speeded } \\
(250 \text { wpm })\end{array}$ & $\begin{array}{l}\text { Rate Fast } \\
(200 \text { wpm }) \\
\end{array}$ & $\begin{array}{l}\text { Rate Normal } \\
(150 \text { wpm })\end{array}$ & Total \\
\hline $\begin{array}{r}1 \\
2 \\
3 \\
4 \\
5 \\
6 \\
7 \\
8 \\
9 \\
10 \\
11 \\
12 \\
13 \\
14 \\
15 \\
16 \\
17 \\
18 \\
19 \\
20 \\
21 \\
22 \\
23 \\
24\end{array}$ & $\begin{array}{l}3 \\
3 \\
3 \\
6 \\
3 \\
2 \\
6 \\
9 \\
8 \\
6 \\
5 \\
6 \\
6 \\
7 \\
9 \\
9 \\
8 \\
7 \\
5 \\
6 \\
6 \\
7 \\
7 \\
6\end{array}$ & $\begin{array}{r}6 \\
6 \\
8 \\
8 \\
8 \\
4 \\
4 \\
5 \\
4 \\
4 \\
4 \\
3 \\
10 \\
9 \\
10 \\
9 \\
8 \\
8 \\
10 \\
8 \\
9 \\
9 \\
7 \\
7\end{array}$ & $\begin{array}{r}8 \\
7 \\
10 \\
10 \\
7 \\
5 \\
7 \\
7 \\
8 \\
6 \\
7 \\
6 \\
9 \\
6 \\
8 \\
8 \\
7 \\
6 \\
9 \\
6 \\
8 \\
8 \\
10 \\
9\end{array}$ & $\begin{array}{r}9 \\
9 \\
8 \\
10 \\
10 \\
6 \\
10 \\
10 \\
9 \\
9 \\
10 \\
8 \\
10 \\
10 \\
9 \\
10 \\
8 \\
9 \\
9 \\
7 \\
6 \\
10 \\
10 \\
8\end{array}$ & $\begin{array}{l}26 \\
25 \\
29 \\
34 \\
28 \\
17 \\
27 \\
31 \\
29 \\
25 \\
26 \\
23 \\
35 \\
32 \\
36 \\
36 \\
31 \\
30 \\
33 \\
27 \\
29 \\
34 \\
34 \\
30\end{array}$ \\
\hline & $\begin{array}{c}143 \\
\mathrm{~T}_{1}\end{array}$ & $\begin{array}{r}168 \\
\mathrm{~T}_{2}\end{array}$ & $\begin{array}{r}182 \\
T_{3}\end{array}$ & $\begin{array}{r}214 \\
T_{4}\end{array}$ & $707=\mathrm{G}$ \\
\hline
\end{tabular}


RAW DATA

GRAND AND TOTAL VALUE SCORES FOR

VARIOUS RATES IN SUBTEST C OF ACLC

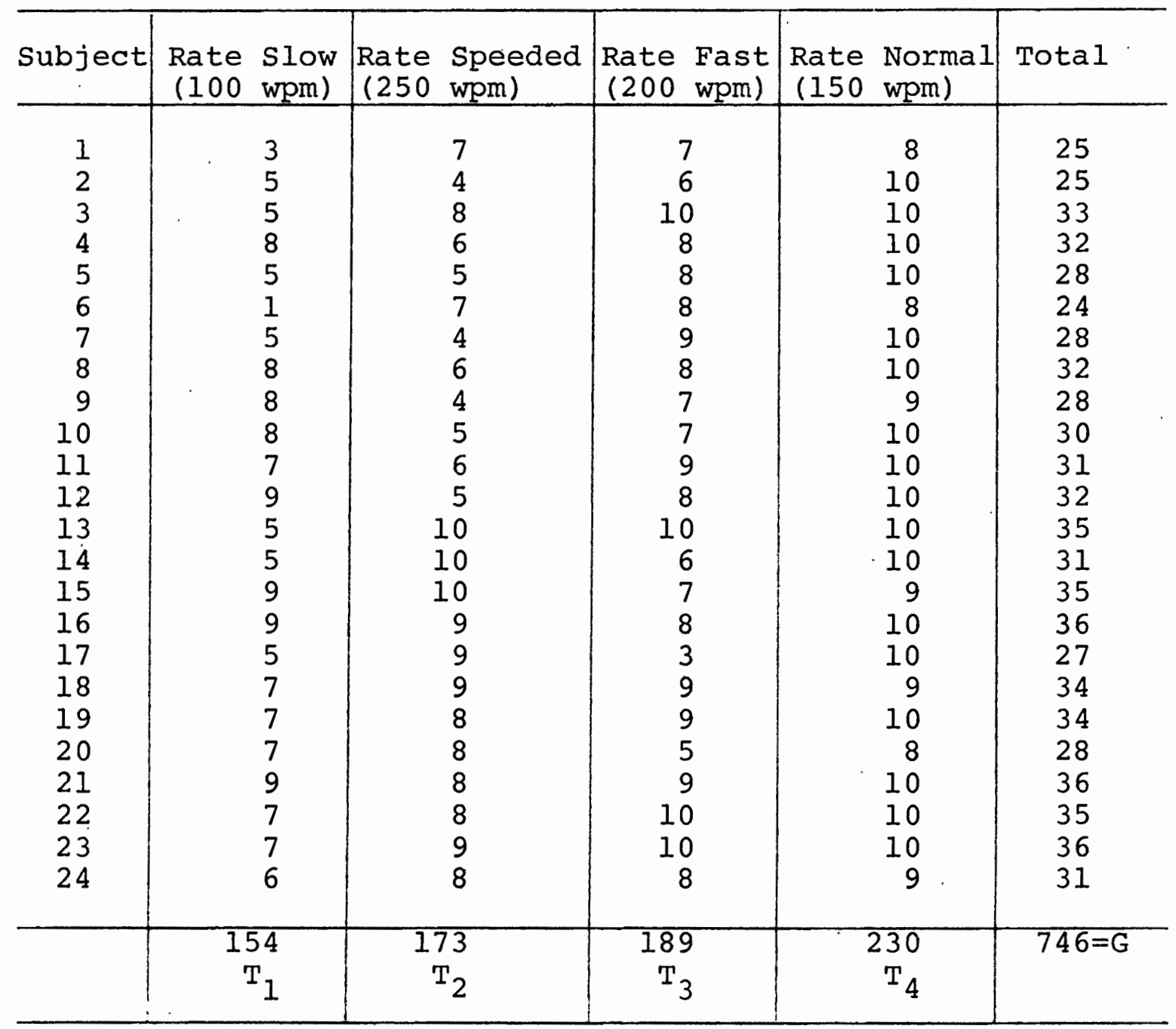


RAW DATA

GRAND AND TOTAL VALUE SCORES FOR

VARIOUS RATES IN SUBTEST B

OF ACLC

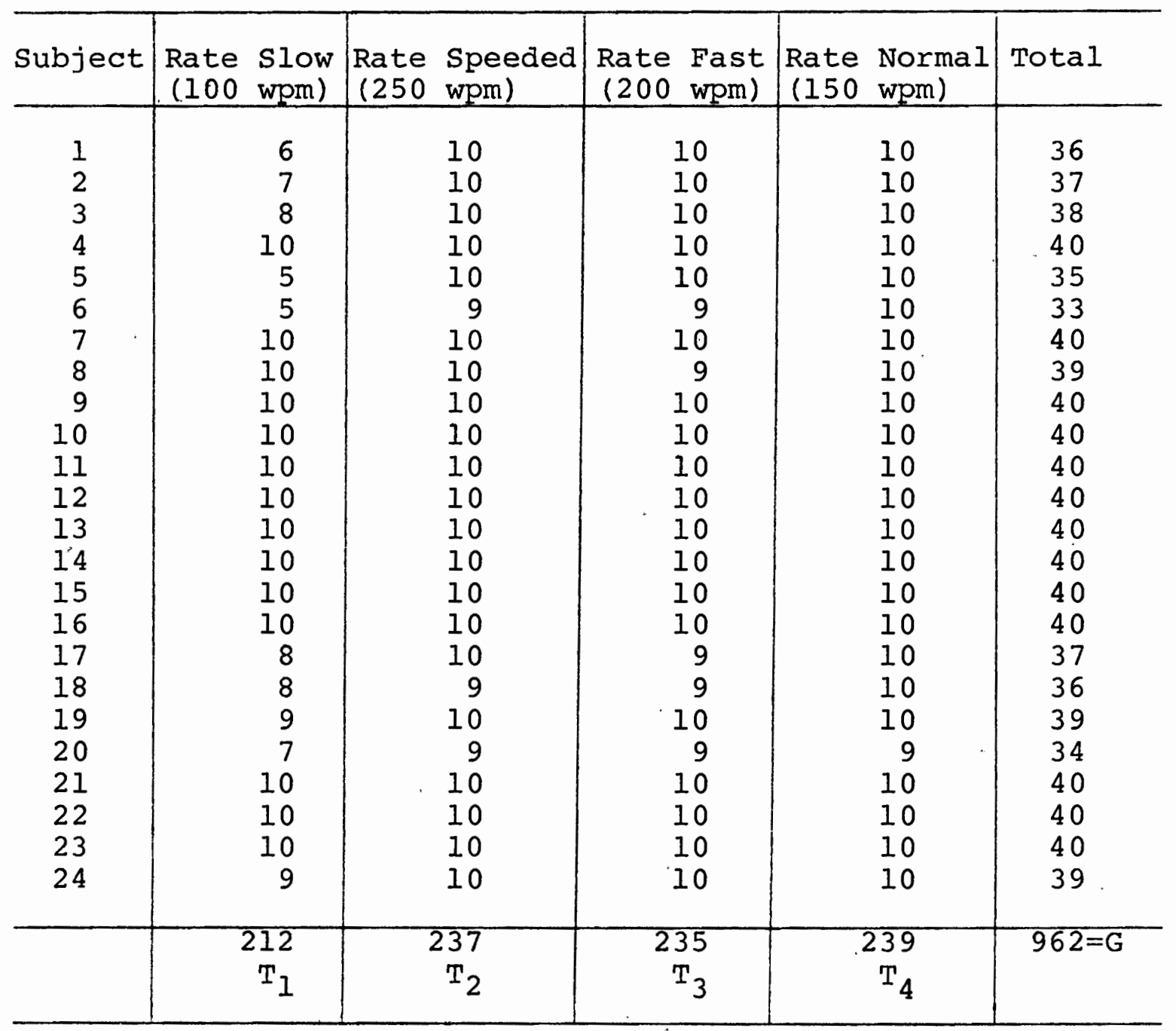


RAW DATA

GRAND AND TOTAL VALUE SCORES FOR

VARIOUS RATES IN SUBTEST A.

OF ACLC

\begin{tabular}{c|c|c|c|c|c}
\hline Subject & $\begin{array}{c}\text { Rate Slow } \\
(100 \text { wpm })\end{array}$ & $\begin{array}{c}\text { Rate Speeded } \\
(250 \text { wpm })\end{array}$ & $\begin{array}{c}\text { Rate Fast } \\
(200 \text { wpm })\end{array}$ & $\begin{array}{c}\text { Rate Normal } \\
(150 \text { wpm })\end{array}$ & Total \\
\hline 1 & 14 & 44 & 48 & 50 & 156 \\
2 & 30 & 47 & 47 & 48 & 172 \\
3 & 36 & 47 & 50 & 50 & 183 \\
4 & 42 & 47 & 50 & 50 & 189 \\
5 & 30 & 44 & 44 & 47 & 165 \\
6 & 17 & 45 & 50 & 48 & 160 \\
7 & 47 & 39 & 47 & 49 & 182 \\
8 & 43 & 35 & 43 & 50 & 171 \\
9 & 47 & 37 & 49 & 49 & 182 \\
10 & 46 & 46 & 49 & 49 & 190 \\
11 & 45 & 44 & 49 & 50 & 188 \\
12 & 45 & 44 & 48 & 50 & 187 \\
13 & 40 & 50 & 50 & 50 & 190 \\
14 & 40 & 47 & 42 & 40 & 178 \\
15 & 45 & 49 & 44 & 48 & 186 \\
16 & 45 & 49 & 47 & 50 & 191 \\
17 & 37 & 43 & 44 & 46 & 170 \\
18 & 40 & 48 & 41 & 46 & 175 \\
19 & 42 & 45 & 50 & 47 & 184 \\
20 & 35 & 46 & 47 & 46 & 174 \\
21 & 42 & 48 & 49 & 50 & 189 \\
22 & 40 & 49 & 50 & 50 & 189 \\
23 & 45 & 44 & 50 & 50 & 189 \\
24 & 47 & 49 & 49 & 47 & 192 \\
& & & & & \\
\hline & 940 & 1086 & 1137 & 1169 & $4332=\mathrm{G}$ \\
& $\mathrm{T} 1$ & $\mathrm{~T} 2$ & $\mathrm{~T} 3$ & $\mathrm{~T} 4$ & \\
\hline & & & & & \\
\hline
\end{tabular}

